\title{
The Function of the Long Dorsal Sacroiliac Ligament
}

\author{
Its Implication for Understanding Low Back Pain
}

\author{
Andry Vleeming, PhD, ${ }^{*}$ Annelies L. Pool-Goudzwaard, BSc, ${ }^{*}$ \\ Dilara Hammudoghlu, MD, ${ }^{*}$ Rob Stoeckart, PhD, ${ }^{*}$ Chris J. Snijders, PhD,† \\ and Jan M. A. Mens, MDł
}

Study Design. In embalmed human bodies the tension of the long dorsal sacroiliac ligament was measured during incremental loading of anatomical structures that are biomechanically relevant.

Objectives. To assess the function of the long dorsal sacroiliac ligament.

Summary of Background Data. In many patients with aspecific low back pain or peripartum pelvic pain, pain is experienced in the region in which the long dorsal sacroiliac ligament is located. It is not well known that the ligament can be easily palpated in the area directly caudal to the posterior superior iliac spine. Data on the functional and clinical importance of this ligament are lacking.

Methods. A dissection study was performed on the sacral and lumbar regions. The tension of the long dorsal sacroiliac ligament ( $n=12$ ) was tested under loading. Tension was measured with a buckle transducer. Several structures, including the erector spinae muscle, the posterior layer of the thoracolumbar fascia, the sacrotuberous ligament, and the sacrum, were incrementally loaded (with forces of $0-50$ newtons). The sacrum was loaded in two directions, causing nutation (ventral rotation of the sacrum relative to the iliac bones) and counternutation (the reverse).

Results. Forced nutation in the sacroiliac joints diminished the tension and forced counternutation increased the tension. Tension in the long dorsal sacroiliac ligament increased during loading of the ipsilateral sacrotuberous ligament and erector spinae muscle. The tension decreased during traction to the gluteus maximus muscle. Tension also decreased during traction to the ipsilateral and contralateral posterior layer of the thoracolumbar fascia in a direction simulating contraction of the latissimus dorsi muscle.

Conclusions. The long dorsal sacroiliac ligament has close anatomical relations with the erector spinae muscle, the posterior layer of the thoracolumbar fascia, and a specific part of the sacrotuberous ligament (tuberoil-

From the *Department of Anatomy, †Department of Biomedical Physics and Technology, and $\neq$ Department of Rehabilitation Medicine, Research Group Musculoskeletal System, Faculty of Medicine and Allied Health Sciences, Erasmus University Rotterdam, The Netherlands.

Acknowledgment date: January 18, 1995

First revision date: May 2, 1995.

Acceptance date: July 18, 1995.

Device status category: 10 . iac ligament). Functionally, it is an important link between legs, spine, and arms. The ligament is tensed when the sacroiliac joints are counternutated and slackened when nutated. The reverse holds for the sacrotuberous ligament. Slackening of the long dorsal sacroiliac ligament can be counterbalanced by both the sacrotuberous ligament and the erector muscle. Pain localized within the boundaries of the long ligament could indicate among other things a spinal condition with sustained counternutation of the sacroiliac joints. In diagnosing patients with aspecific low back pain or peripartum pelvic pain, the long dorsal sacroiliac ligament should not be neglected. Even in cases of arthrodesis of the sacroiliac joints, tension in the long ligament can still be altered by different structures. [Key words: low back pain, sacroiliac joint, anatomy, biomechanics, long dorsal sacroiliac ligament, tubero-iliac ligament] Spine 1996;21:556-562

\section{Introduction}

The understanding of low back pain will be seriously hampered by neglecting the sacroiliac (SI)-joints as essential elements for load transfer between spine and legs. In fact, recent studies show that the SI-joints are a significant source of pain in patients with chronic low back pain. ${ }^{2,3,5,7,8,11,18,20,21}$ Generally, pain in the area of the SI-joints is not regarded as part of low back pain. This is due to incomplete knowledge of the specific anatomy of the SI-joints among many clinicians. In an international survey among medical practitioners, ${ }^{31}$ less than $10 \%$ could identify the long dorsal sacroiliac ligament (long ligament), which is easily palpable in the area directly caudal to the posterior superior iliac spine (PSIS). This ligament connects the PSIS (and a small part of the iliac crest) with the lateral crest of the third and fourth segment of the sacrum. ${ }^{9}$ In standard anatomical textbooks the location of the long ligament and its relation with the sacrotuberous ligament varies widely. Directly caudal to the PSIS the ligament is covered by the fascia of the gluteus maximus muscle. Here, the ligament is so solid and stout that one can easily think a bony structure is being palpated. 
The region directly caudal to the PSIS is of special interest because in a recent study on patients $(n=394)$ with peripartum pelvic pain, $42 \%$ indicated pain in this area. ${ }^{14}$ Furthermore, in patients with aspecific low back pain $(n=61), 44 \%$ of the women experienced pain, mostly bilaterally, when palpated in this area. ${ }^{16}$ Of the men, $47 \%$ experienced pain in this area, approximately half of them bilaterally. Increased tension of the long ligament could clarify why pain is specifically felt in the area caudal to the PSIS. The question is raised whether the tension of the long ligament can be increased by displacement in the SI-joint and/or by muscle activity. In that case the long ligament might be important for load transfer. To our knowledge no literature exists on the function of this prominent ligament.

\section{Materials and Methods}

Anatomy. A dissection study was performed on specimens of five males and one female, aged 70-92 years, embalmed by vascular perfusion with a solution containing $2.2 \%$ formaldehyde. After 6 weeks immersion, the specimens were transferred to a solution with phenoxyethanol. During the experiments the specimens were lying prone and fixed to the research table by two belts in the sagittal plane running centrally over the iliac crests.

By careful dissection, the fascia of the gluteus maximus muscle and the posterior layer of the thoracolumbar fascia were exposed. The fascia of the gluteus maximus muscle and its fibers were removed by blunt dissection, leaving the connection between muscle and dorsal sacroiliac ligaments intact. The anatomical relationships of the long ligament were described with special reference to its connections with superficially the gluteus maximus, sacrotuberous ligament, and the posterior layer of the thoracolumbar fascia, and medially the aponeurosis of the erector spinae (ES).

Biomechanics. To study the biomechanical relation between long ligament and connected structures, a custom-made frame was used. Measurements were performed under controlled conditions, including room temperature and air humidity. Forces were simulated with weights from $0-50$ newtons $(\mathrm{N})$, with increments of $10 \mathrm{~N}$. Unilateral forces were applied, left and right, to the following structures:

biceps femoris, impact site $5 \mathrm{~cm}$ caudal to the ischial tuberosity

sacrotuberous ligament, impact site $4 \mathrm{~cm}$ cranial to the ischial tuberosity

fascia and superficial fibers of the gluteus maximus, impact site $2 \mathrm{~cm}$ lateral of the long ligament

posterior layer of the thoracolumbar fascia, impact site $4 \mathrm{~cm}$ toward the cranium from the PSIS.

During traction to the thoracolumbar fascia, the effect of traction was measured both on the ipsi- and contralateral long ligaments. In other cases tension was measured only in the ipsilateral long ligament. Ligament tension was recorded by a custom-made "buckle" transducer $(1.2 \times 4 \mathrm{~cm})^{1,19}$ tailored to the size of the ligament and centered over the long ligament (Figure 1). It cannot be ruled out that at the site of the buckle

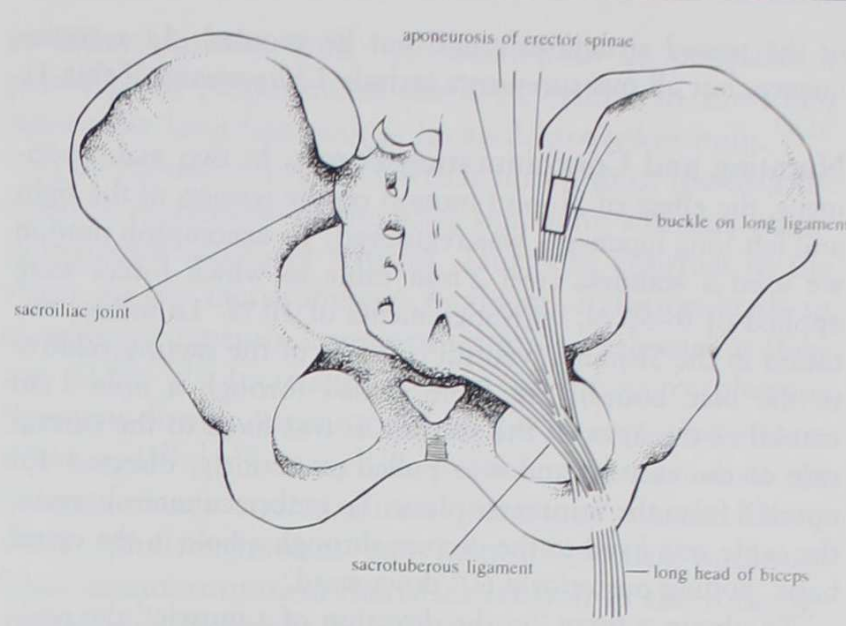

Figure 1. Schematic drawing of the relations between pelvis, sacrotuberous ligament, and long ligament.

some fibers occur which are directly derived from the ischial tuberosity. The transducer could be applied with minimal disruption of the anatomical integrity of the ligament. For this goal, a stainless steel "U" bar was constructed to connect the transducer to the ligament.

Signals from the buckle transducer were amplified by a custom-made bridge amplifier and registered by a fourchannel plotter (BBC Goerz Metrawatt SE 620; Gossen Metrawat, Neurenberg, Germany). The transducer was extensively tested and showed a high test-retest reliability.

To simulate the action of the latissimus dorsi and the transverse abdominal muscle in tensing the thoracolumbar fascia through the lateral raphe, ${ }^{33}$ forces were applied to the posterior layer of the thoracolumbar fascia. For the latissimus dorsi the forces were directed to craniolateral $\left(60^{\circ}\right.$ relative to the spine), for the transverse abdominal to lateral $\left(90^{\circ}\right.$ relative to the spine).

To expose the ES muscle, subsequently a midsagittal incision of $3 \mathrm{~cm}$ was made through the thoracolumbar fascia. Traction was applied to the aponeurosis and muscle fibers of the ES muscle, at an impact site $5 \mathrm{~cm}$ toward the cranium from the PSIS.

All measurements were repeated three times. Slight damage

Table 1. Relations Between Loads Applied and Tension of the Long Ligament

\begin{tabular}{lrccc}
\hline Structure & $\begin{array}{c}\text { Estimated } \\
\text { Slope* }\end{array}$ & SE & $P$ Value & $\begin{array}{c}\text { No. of } \\
\text { Ligaments }\end{array}$ \\
\hline Sacrotuberal ligament & 1.2495 & 0.0365 & $<0.0005$ & 12 \\
Erector spinae & 0.3441 & 0.0323 & $<0.0005$ & 12 \\
Gluteus maximus & -0.1422 & 0.0353 & $<0.0005$ & 8 \\
Biceps femoris & 0.0151 & 0.0395 & 0.702 & 6 \\
TLFipsi 60 & -0.2058 & 0.0323 & $<0.0005$ & 11 \\
TLFipsi 90 & -0.0509 & 0.0323 & 0.115 & 8 \\
TLFcontra 60 & -0.0909 & 0.0323 & 0.005 & 9 \\
TLFcontra 90 $90^{\circ}$ & 0.0188 & 0.0395 & 0.634 & 6 \\
Nutation & -0.5631 & 0.0255 & $<0.0005$ & 4 \\
Counternutation & 0.4323 & 0.0249 & $<0.0005$ & 4 \\
\hline
\end{tabular}

* Estimated slope refers to the separate slope coefficients with the forces applied.

TLF $=$ thoracolumbar fascia (posterior layer) 
of the tensed structures could not be avoided. As a consequence, not all measurements include 12 ligaments (Table 1).

Nutating and Contranutating Forces. In two male specimens, the effect of SI-joint motion on the tension of the right and left long ligaments was registered. To accomplish motion we used a stainless steel $2 \mathrm{~mm}$ cable to which forces were applied of $0-50 \mathrm{~N}$, with increments of $10 \mathrm{~N}$. To induce nutation in the SI-joints (ventral rotation of the sacrum relative to the iliac bones), the cable passed through a hole $2 \mathrm{~cm}$ cranial of the apex of the sacrum. It was fixed to the ventral side of the sacrum and was pulled posteriorly, directed $40^{\circ}$ upward from the transverse plane. To induce counternutation, the cable was fixed to the sacrum through a hole in the sacral basis, pulling posteriorly $60^{\circ}$ downward.

To obtain a force "in the direction of a muscle" the position of the embalmed specimen was changed with respect to the direction of a tightened rope while observing the distribution of the force over the muscle fibers. The forgoing holds for the thoracolumbar fascia as well. Unequal distribution manifests itself in asymmetry and in unilateral bulging. The position of the specimen was changed until equal distribution was obtained.

Because the fixation of the almost intact pelvis with straps is not rigid, some deformation depending on the applied load may be expected. However, the innominates were not screwed to the frame, since Miller et al ${ }^{15}$ demonstrated "that fixation of the hip bones which precludes lateral separation of the iliac from the sacrum results in considerable restriction of the mobility of the SI-joints."

It is assumed that the variation in the direction of the applied forces, due to the influences mentioned before, has no influence on the results of the study, because the direction of the forces was at the dorsal side of the axis of the sacroiliac joints in all tests.

Statistical Analysis. To analyze the effect of loading on tension of the long ligament, repeated measures analysis of variance was used. The relation between loading force and tension of the long ligament is assumed to be linear with no intercept. For the within-covariance matrix of the repeated measurements a linear structure was specified. The statistical analysis is performed on the arithmetic average of the buckle output of the right and left long ligaments. The explanatory variables in the analysis are the forces applied and the interaction of force and loaded structure.

\section{- Results}

\section{Anatomy}

In all specimens parts of the fascia of the gluteus maximus are continuous with the superficial lamina of the posterior layer of the thoracolumbar fascia. The deep fascia of the gluteus maximus and the muscle itself show multiple connections with the sacrotuberous ligament. It is also connected to the long ligament.

At the cranial side the long ligament is attached to the PSIS and the adjacent part of the ilium, at the caudal side to the lateral crest of the third and fourth sacral segments. In some specimens fibers pass also to the fifth sacral segment. From the sites of attachment on the sacrum fibers pass to the coccyx. They are not considered to be part of the long ligament.

The lateral expansion of the long ligament in the region directly caudal to the PSIS varies between 15$30 \mathrm{~mm}$. The length, measured between to the PSIS and the third and fourth sacral segments, varies between $42-75 \mathrm{~mm}$. The lateral part of the long ligament is continuous with fibers passing between ischial tuberosity and iliac bone. The variation is wide. Medial fibers of the long ligament are connected to the deep lamina of the posterior layer of the thoracolumbar fascia and to the aponeurosis of the ES muscle. After dissection of the ES aponeurosis, the connections between ligament and fibers of the multifidus muscle become visible.

\section{Biomechanics}

The effect of traction to the sacrotuberous ligament, the aponeurosis of the ES, the gluteus maximus, and the long head of the biceps femoris on tension of the long ligament is shown in Figure 2. The results can be summarized as follows:

1. Tension in the long ligament increases strongly during incremental loading of the ipsilateral sacrotuberous ligament.

2. The same holds for incremental loading of the ipsilateral part of the ES muscle but the effect is about $25 \%$ of the values obtained with loading of the sacrotuberous ligament.

3 . Tension of the long ligament decreases with incremental loading of the ipsilateral gluteus maximus.

4. The mean effect of loading the unilateral biceps femoris is negligible.

Figure 2 and Table 1 show furthermore that the statistical assumption of straight lines through the origin is a valid one for each of the loaded structures. The same holds for loading of the thoracolumbar fascia. The slopes of the sacrotuberous ligament, the ES muscle, the gluteus maximus, and the thoracolumbar fascia at $60^{\circ}$,

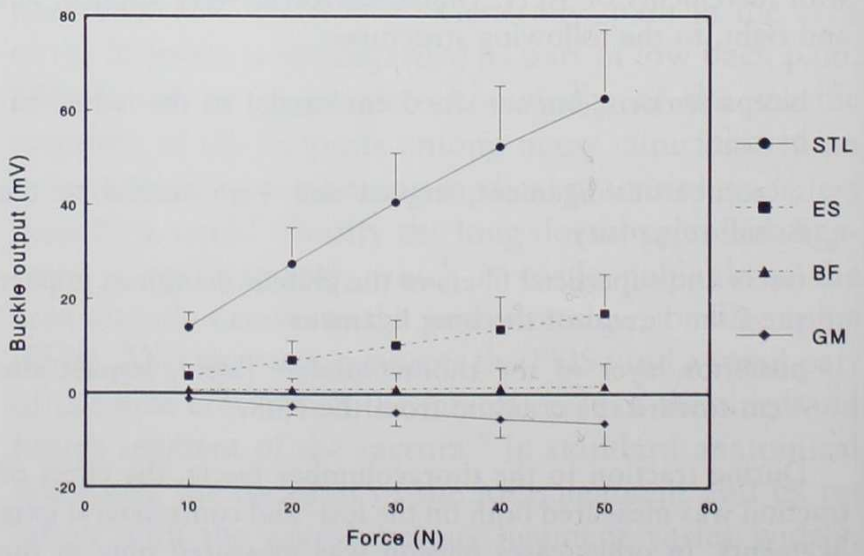

Figure 2. Relation between forces applied (in Newtons) and tension of the long ligament (in $\mathrm{mV}$ ). STL = sacrotuberous ligament. $\mathrm{ES}=$ erector spinae muscle. $\mathrm{BF}=$ biceps femoris muscle. $\mathrm{GM}=$ gluteus maximus muscle. 


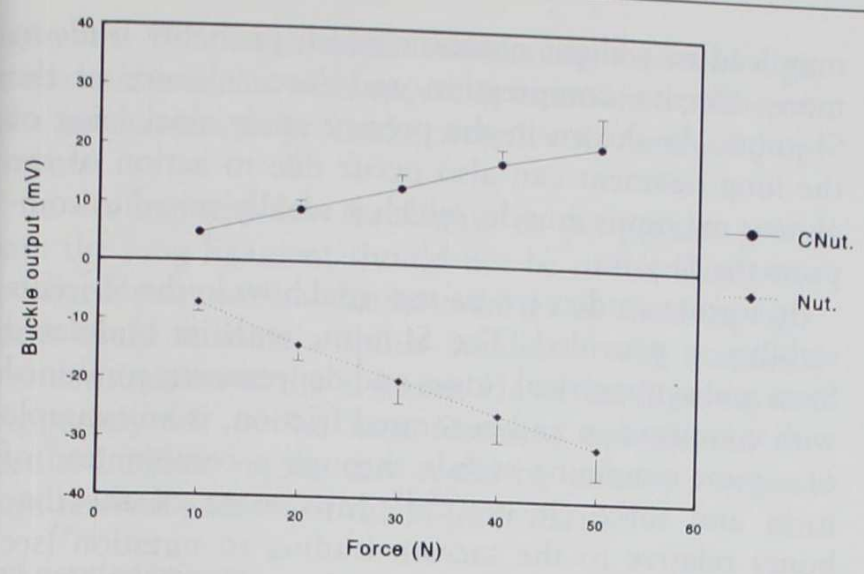

Figure 3. Relation between nutating (Nut.) and counternutating (CNut.) forces and tension of the long ligament.

both ipsilaterally and contralaterally, are significantly different from zero. Tension increases by loading the sacrotuberous ligament and the ES muscle. It decreases by loading the gluteus maximus muscle and the thoracolumbar fascia in the direction of the latissimus dorsi muscle. Furthermore, incremental loading of the sacrum leading to nutation causes a statistically significant decrease of tension, counternutation an increase (Figure 3, Table 1).

The extent of the effect on the long ligament of loading the sacrotuberous ligament and the ES muscle is significantly different $(P<0.0005)$. This also holds for the effect of loading the gluteus maximus and the biceps femoris $(P=0.003)$.

\section{Discussion}

In the literature, specific data on the functional and clinical relevance of the long ligament are not available. In several anatomical atlases and textbooks the long ligament and the sacrotuberous ligament are portrayed as fully continuous ligaments. Generally the drawings convey the impression that the ligaments have identical functions. As shown by the contrasting effects of nutation and of contranutation on these ligaments, this is not the case. Essentially the long ligament connects sacrum and PSIS, whereas the main part of the sacrotuberous ligament connects sacrum and ischial tuberosity. However, part of the fibers derived from the ischial tuberosity pass to the iliac bone (Figure 1). These fibers function as site of origin for the gluteus maximus muscle. Generally they are denoted as part of the sacrotuberous ligament, although tuberoiliac ligament would be more appropriate. In the Nomina Anatomica such a ligament does not exist. In fact, this also holds for the long (dorsal sacroiliac) ligament, reflecting one of the problems of topographical anatomy.

The observations presented in this study imply that the tension of the long ligament can be altered by displacement of the SI-joint as well as by action of various muscles. These observations are of special interest since in many patients with low back pain or peripartum pelvic pain, palpation of the area caudal to the PSIS, where the long ligament is located, provokes pain. ${ }^{14,16}$

The present study shows that nutation of the SI-joint induces relaxation of the long ligament whereas counternutation increases tension. This is in contrast to the effect on the sacrotuberous ligament: nutation leads to increase of tension, counternutation to relaxation (Figure 4). ${ }^{26,27,36}$ Increased tension in the sacrotuberous ligament during nutation can be due to sacroiliac movement itself ${ }^{2,27,36}$ as well as to increased tension of the biceps femoris and/or gluteus maximus muscle. Obviously, this mechanism can help to control nutation. Since counternutation increases tension in the long ligament, this ligament can assist in controlling counternutation (Figure 4A).

Apparently ligaments with opposite functions such as the long and sacrotuberous ligaments do not interact in
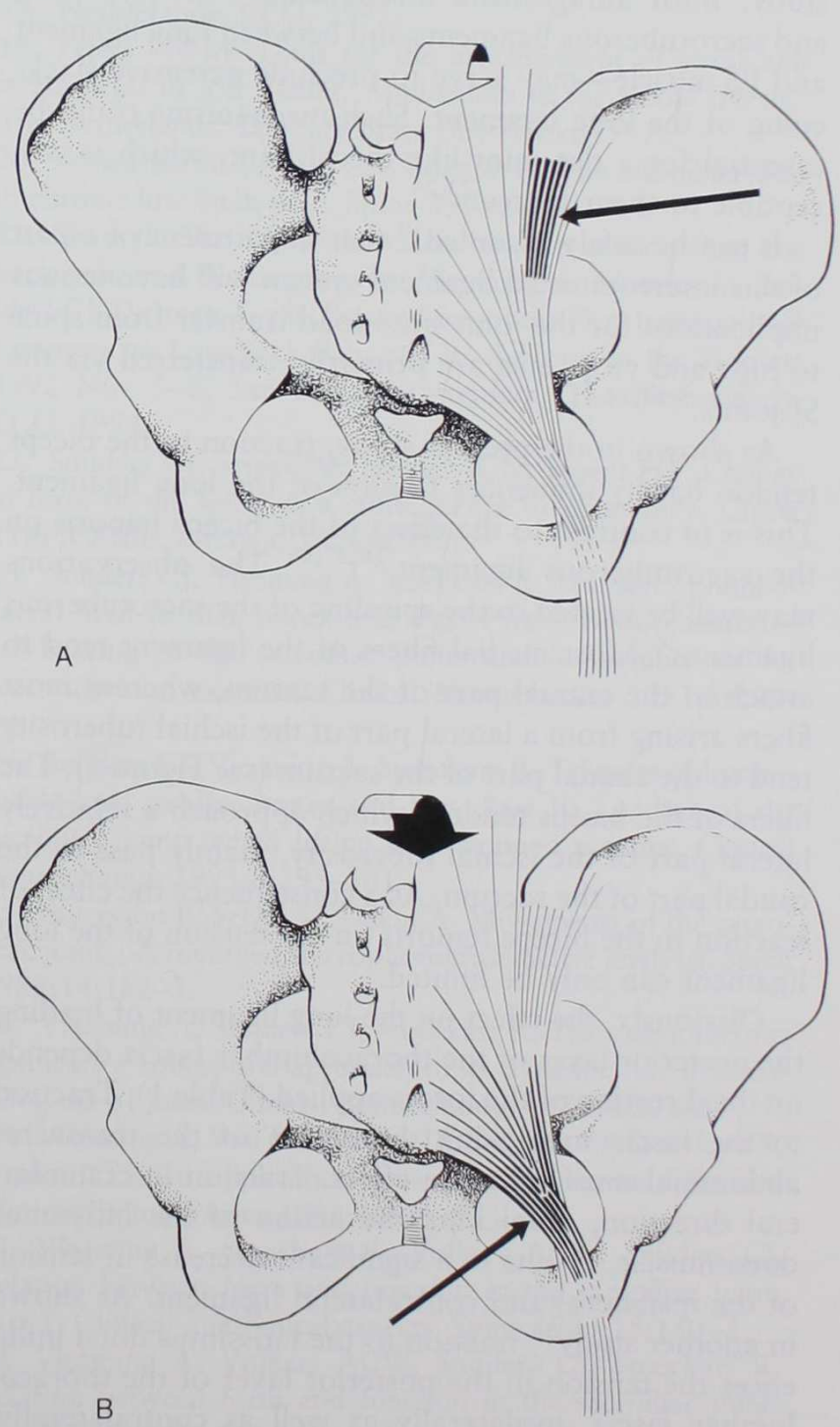

Figure 4. Schematic drawing of the controlling effect of the long ligament in counternutation (A) and of the sacrotuberous ligament in nutation (B). 
a simple way. After all, loading of the sacrotuberous ligament leads to increased tension of the long ligament. This effect will be due to the connections between long ligament and tuberoiliac ligament and possibly also to a counternutating force generated by the loading of the sacrotuberous ligament. A comparable complex relation may hold for the long ligament and the ES. Since the caudal part of the ES muscle is mainly connected to the sacrum, ${ }^{12,13}$ action of the ES muscle will induce nutation. As a result the long ligament will slacken. However, the present study shows increase of tension in the long ligament by traction to the ES muscle. This counterbalancing effect is due to the connections between ES muscle and long ligament and opposes the slackening. In vivo this effect may be smaller because of the moment of force acting on the sacrum is raised by the pull of the ES muscle and the resulting compression force on the spine. ${ }^{24}$ This spinal compression was not applied in this study. Both antagonistic mechanisms-between long and sacrotuberous ligaments and between long ligament and ES muscle-may serve to preclude extensive slackening of the long ligament. Such mechanisms could be essential for a flat joint like the SI-joint, which is susceptible to shear forces. ${ }^{23,24}$

It can be safely assumed ${ }^{30}$ that impairment of a part of this interconnected ligament system will have serious implications for the joint since load transfer from spine to hips and vice versa are primarily transferred via the SI-joints. ${ }^{4,23,24}$

As shown in the present study, traction to the biceps tendon hardly influences tension of the long ligament. This is in contrast to the effect of the biceps femoris on the sacrotuberous ligament. ${ }^{26,27,36}$ The observations may well be related to the spiraling of the sacrotuberous ligament. ${ }^{36}$ Most medial fibers of the ligament tend to attach to the cranial part of the sacrum, whereas most fibers arising from a lateral part of the ischial tuberosity tend to the caudal part of the sacrum (see Figure 1). The fibers of the biceps tendon, which approach a relatively lateral part of the ischial tuberosity, mainly pass to the caudal part of the sacrum. As a consequence the effect of traction to the biceps femoris on the tension of the long ligament can only be limited.

Obviously, the effect on the long ligament of loading the posterior layer of the thoracolumbar fascia depends on the direction of the forces applied (Table 1). Traction to the fascia mimicking the action of the transverse abdominal muscle has no effect. Traction in craniolateral direction, mimicking the action of the latissimus dorsi muscle, results in a significant decrease in tension of the ipsilateral and contralateral ligament. As shown in another study ${ }^{33}$ traction to the latissimus dorsi influences the tension in the posterior layer of the thoracolumbar fascia, ipsilaterally as well as contralaterally, especially below the level of L4. Thus slackening of the long ligament could be the result of increased tension in the posterior layer by the latissimus dorsi. This itself may lead to a slight nutation which probably leads to more effective compression and force closure of the SI-joints. As shown in the present study slackening of the long ligament can also occur due to action of the gluteus maximus muscle, which is ideally suited to compress the SI-joint.

In former studies it was reported how in the SI-joints stability is provided. The SI-joint, with its undulated form and symmetrical ridges and depressions, combined with compression and generated friction, is an example of a joint remaining stabile through a combination of form and force closure. ${ }^{28,29}$ Movement of the iliac bones relative to the sacrum leading to nutation (see Figure 4B) increases the tension in sacrotuberous (and interosseous) ligaments and thus will compress the joint. ${ }^{27}$ It has to be added that the range of movement in the SI-joint differs intra-individually; normally, this range is very small. $6,10,25,32,35$

It is inviting to draw prompt conclusions when palpation of the long ligament directly caudal to the PSIS is painful. This must be avoided for the following reason: Pain in this area may be due to pain referred from the SI-joint itself ${ }^{7,8}$ but also to counternutation of the SIjoints. Counternutation is part of a pattern of flattening the lumbar spine, ${ }^{6,10,25}$ which occurs especially late in pregnancy when women counterbalance the weight of the foetus. ${ }^{22}$ However, such a posture combined with counternutation could also result from a pain-withdrawal-reaction to impairment elsewhere in the system. Hence, even specific pain of the long ligament could be a side effect. An example of such a condition could be the following: Pain of the pubic symphysis following delivery ${ }^{14,17}$ could preclude normal lumbar lordosis and hence nutation due to pain of an irritated symphysis. After all, lumbar lordosis leads to nutation in the SI-joints. 6,10,25,32,35 Nutation implies that the left and right PSIS approach each other slightly while the pubic symphysis is caudally extended and cranially compressed. ${ }^{10,34}$ In this example, the patient will avoid nutation and flattens the lower spine, leading to sustained tension and pain in the long ligament. It seems justified to conclude that when palpation of the long ligament is painful, one must examine whether extension of the lower spine and nutation in the SI-joints is possible.

\section{Conclusion}

Anatomically, the long ligament, which can be easily palpated directly caudal to the PSIS, can be viewed as a pelvic structure. However, the ligament has close relations with among others the erector spinae muscle, the posterior layer of the thoracolumbar fascia and the sacrotuberous ligament. Therefore, functionally it is an important link between legs, spine and arms.

The long ligament is tensed when the SI-joints are counternutated and slackened when nutated. During nutation both erector muscle and sacrotuberous ligament can counterbalance the slackening of the long 
ligament. The anatomical connections between ligaments and muscles with opposing functions could serve as a mechanism to preclude excessive slackening of ligaments.

In dealing with low back pain or peripartum pelvic pain the long ligament should not be overlooked since localized pain within the boundaries of the long ligament could indicate a spinal condition with sustained counternutation of the SI-joints. However, if pain is not exclusively felt in the long ligament but also in the medial buttock region this could be part of a typical pain referral pattern of the SI-joint itself., 7,8

\section{Acknowledgments}

The authors thank P.G.M. Mulder, J.V. de Bakker, G.A. Hoek van Dijke, A. van Randen, J.G. Velkers, C.A.C. Entius, C. de Vries, and M.G. van Kruining for their assistance.

\section{References}

1. Barry D, Ahmed AM. Design and performance of a modified buckle transducer for the measurement of ligament tension. J Biomech Eng 1986;108:149-52.

2. Bernard TN, Cassidy JD. The sacroiliac joint syndrome, pathophysiology, diagnosis and management. In: Vleeming A, Mooney V, Snijders CJ, Dorman T, eds. Proceedings of the First International Congress on Low Back Pain and its Relation to the SI-joint; 1992 Nov 5-6, San Diego. Rotterdam, The Netherlands: ECO, 1992:119-43.

3. Cassidy JD. The pathoanatomy and clinical significance of the sacroiliac joints. J Manipulative Physiol Ther 1992;15: 41-2.

4. Dalstra M, Huiskes R. Load transfer across the pelvic bone. In: Leijn, Nijmegan. Biomechanical aspects of the pelvic bone and design criteria for acetabular protheses [thesis]. The Netherlands: University Nijmegen, 1993.

5. DonTigny R. Dysfunction of the sacroiliac joint and its treatment. J Orthop Sports Phys Ther 1979;1:23-35.

6. Egund N, Ollson TH, Schmid H, Selvik G. Movements in the sacroiliac joints demonstrated with roentgen stereofotogrammetry. Acta Radiologica Diagnosis 1978;19:833-46.

7. Fortin JD, Dwyer AP, West S, Pier J. Sacroiliac joint: Pain referral maps upon applying a new injection/arthrography technique. Part 1: Asymptomatic volunteers. Spine 1994;19: 1475-82.

8. Fortin JD, Aprill CN, Ponthieux B, Pier J. Sacroiliac joint: Pain referral maps upon applying a new injection/arthrography technique. Part 2: Clinical evaluation. Spine 1994;19: 1483-9.

9. Gray's Anatomy: Descriptive and applied. Johnston TB, Whillis J, eds. London: Longmans, Green \& Co., 1944.

10. Lavignolle B, Vital JM, Senegas J, Destandau J, Toson J, Bouyx B, et al. An approach to the functional anatomy of the sacroiliac joints in vivo. Anatomica Clinica 1983;5:169-76.

11. Lee D. The pelvic girdle. Edinburgh, London, Melbourne, New York: Churchill Livingstone, 1989.

12. MacIntosch JE, Bogduk N. The biomechanics of the lumbar multifidus. Clinical Biomechanics 1986;1:205-13.

13. MacIntosch JE, Bogduk N. The attachments of the lumbar erector. Spine 1991;16:783-92.
14. Mens JMA, Stam HJ, Stoeckart R, Vleeming A, Snijders CJ. Peripartum pelvic pain; a report of the analysis of an inquiry among patients of a Dutch patient society. In: Vleeming A, V Mooney, Snijders CJ, Dorman T, eds. Proceedings of the First International Congress on Low Back Pain and its Relation to the SI-joint; 1992 Nov 5-6, San Diego. Rotterdam, The Netherlands: ECO, 1992.

15. Miller JAA, Schultz AB, Andersson GBJ. Load-displacement behavior of sacroiliac joints. J Orthop Res 1987;5:92-
101 .

16. Njoo, KH. Regional pain syndromes in patients with low back pain. In preparation.

17. Östgaard HC, Andersson GBJ, Schultz AB, Miller JAA. Influence of some biomechanical factors on low-back pain in pregnancy. Spine $1993 ; 18 ; 61-5$.

18. Paris VP. Differential diagnosis of sacroiliac joint from lumbar spine dysfunction. In: Vleeming A, Mooney V, Snijders CJ, Dorman T, eds. Proceedings of the First Interdisciplinary World Congress on Low Back Pain and its Relation to the sacroiliac joint; 1992 Nov 5-6, San Diego. Rotterdam, The Netherlands: ECO, 1992.

19. Peters GWM. Tools for the measurement of stress and strain fields in soft tissues: Application to the elbow [thesis]. The Netherlands: Limburg State University, 1987.

20. Schwarzer AC, Aprill CN, Bogduk N. The sacroiliac joint in chronic low back pain. Spine 1995;20:31-7.

21. Shaw JL. The role of the sacroiliac joint as a cause of low back pain and dysfunction. In: Vleeming A, Mooney V, Snijders CJ, Dorman T, eds. Proceedings of the First International Congress on Low Back Pain and its Relation to the SI-joint; 1992 Nov 5-6, San Diego. Rotterdam, The Netherlands: ECO, 1992.

22. Snijders CJ, Seroo JM, Snijder JGN, Hoedt HT. Change in form of the spine as a consequence of pregnancy. Digest 11th ICMBE, Ottawa, 1976:670-1.

23. Snijders CJ, Vleeming A, Stoeckart R. Transfer of lumbosacral load to iliac bones and legs. Part I: Biomechanics of self-bracing of the sacroiliac joints and its significance for treatment and exercise. Clinical Biomechanics 1993;8:28594.

24. Snijders CJ, Vleeming A, Stoeckart R. Transfer of lumbosacral load to iliac bones and legs. Part II: Loading of the sacroiliac joints when lifting in a stooped posture. Clinical Biomechanics 1993;8:295-301.

25. Sturesson B, Selvik G, Udén, A. Movements of the sacroiliac joints: A roentgen stereophotogrammetric analysis. Spine $1989 ; 14: 162-5$.

26. Vleeming A, Snijders CJ, Stoeckart R. The sacrotuberous ligament: a conceptual approach to its dynamic role in stabilizing the SI-joint. Clinical Biomechanics 1989;4:201-3.

27. Vleeming A, Van Wingerden JP, Snijders CJ, Stoeckart R, Stijnen T. Load application to the sacrotuberous ligament. Clinical Biomechanics 1989;4:204-9.

28. Vleeming A, Stoeckart R, Volkers ACW, Snijders CJ. Relation between form and function in the sacroiliac joint: Part 1. Clinical anatomical aspects. Spine 1990;15:130-2.

29. Vleeming A, Volkers ACW, Snijders CJ, Stoeckart R. Relation between form and function in the sacroiliac joint: Part 2. Biomechanical aspects. Spine 1990;15:133-6.

30. Vleeming A, Buyruk HM, Stoeckart R, Karamursel S, Snijders CJ. Towards an integrated therapy for peripartum pelvic instability. Am J Obstet Gynecol 1992;166(4):1243-7. 
31. Vleeming A, Pool-Goudzwaard AL, Stoeckart R, Snijders CJ, Wingerden JP van. Towards a better understanding of the etiology of low back pain. Proceedings of the First International Congress on Low Back Pain and its Relation to the SI-joint; 1992 Nov 5-6, San Diego. Rotterdam, The Netherlands: ECO, 1992.

32. Vleeming A, Wingerden van JP, Snijders CJ, Stoeckart R, Dijkstra PF, Stijnen T. Mobility in the SI-joints in the elderly: a kinematic and roentgenologic study. Clinical Biomechanics 1992;7:170-6.

33. Vleeming A, Pool-Goudzwaard AL, Stoeckart R, Snijders CJ, Wingerden JP van. The posterior layer of the thoracolumbar fascia: Its function in load transfer from spine to legs. Spine 1995;20:753-8.

34. Walheim GG, Selvik G. Mobility of the pubic symphysis. In vivo measurements with an electromechanic method and a roentgen stereophotogrammetic method. Clin Orthop 1984; 191:129-35.
35. Weisl H. The movements of the sacroiliac joints. Acta Anatomica 1955;23:80-91.

36. Wingerden JP van, Vleeming A, Snijders CJ, Stoeckart R. A functional-anatomical approach to the spine-pelvis mechanism: interaction between the biceps femoris muscle and the sacrotuberous ligament. Eur Spine J 1993;2:140-4.

\section{Address reprint requests to}

Andry Vleeming, $\mathrm{PhD}$ Faculty of Medicine and Allied Health Sciences Erasmus University Rotterdam P.O. Box 1738 3000 DR Rotterdam The Netherlands 